\title{
O lugar do QuANTITATIVo Na PESQuisa CARTOGRÁfica
}

\author{
Janaina Mariano César ${ }^{I \star}$ Fabio Hebert da SilvaI ${ }^{I \star \star}$ \\ Pedro Paulo Gastalho de Bicalholll $\star \star \star ~$ \\ ${ }^{I}$ Universidade Federal do Espírito Santo, Vitória, ES - Brasil \\ II Universidade Federal Fluminense, Campos, RJ - Brasil \\ ${ }^{I I I}$ Universidade Federal do Rio de Janeiro, Rio de Janeiro, RJ - Brasil
}

\begin{abstract}
Resumo
Este texto se propõe discutir as noções de qualitativo e quantitativo no âmbito da pesquisa cartográfica, com ênfase neste último. Estas estão articuladas na direção ético-política de um plano de inseparabilidade entre formas e forças, não restritas à perspectiva dicotômica entre "quali" e "quanti". A partir de dois casos de pesquisa, em suas especificas estratégias, um teste psicológico e um questionário de medição de transtornos mentais leves busca problematizar os efeitos da operação do quantitativo como uma das pistas possiveis ao método da cartografia: a noção de quantitativo como quantum de forças e do qualitativo como diferencial entre quanta de forças, imiscuídas na produção do real.
\end{abstract}

Palavras-chave: metodologia de pesquisa; método da cartografia; quantitativo; qualitativo.

\section{THE PLACE OF QUANTITATIVE IN CARTOGRAPHIC RESEARCH}

\begin{abstract}
This paper proposes to discuss the notions of quality and quantity within the cartographic research, with emphasis on the latter. These are articulated in ethicalpolitical direction of an inseparability plan of forms and forces, not restricted to dichotomous perspective between "quality" and "quantity". From two cases of research in their specific strategies, a psychological test and a questionnaire measuring mild mental disorders, seeks to problematize the effects of quantitative operation as one of the possible clues to the method of cartography: the notion

^ Psicóloga. Possui especialização em Transdisciplinaridade e Clínica, mestrado em Psicologia pela Universidade Federal Fluminense. Atualmente é doutoranda do Programa de Pósgraduação em Educação- PPGE da Universidade Federal do Espírito Santo.

E-mail:jhanainacesar@gmail.com

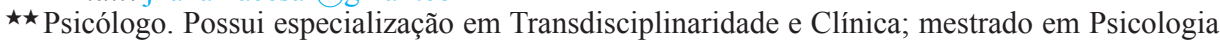
pela Universidade Federal Fluminense, doutorado em Educação pela Universidade Federal do Espírito Santo. Docente da Universidade Federal Fluminense (Campos/RJ), Psicologia. E-mail: fabiohebert@gmail.com

$\star \star \star$ Psicólogo. Possui especialização em Psicologia Jurídica pela Universidade do Estado do Rio de Janeiro, mestrado e doutorado em Psicologia pela Universidade Federal do Rio de Janeiro. Professor Adjunto do Instituto de Psicologia e do Programa de Pós-Graduação em Psicologia da Universidade Federal do Rio de Janeiro. Endereço: Universidade Federal do Rio de Janeiro, Instituto de Psicologia. Av. Pasteur, 250 - Pavilhão Nilton Campos - Campus Praia Vermelha. Urca - Rio de Janeiro, RJ - Brasil. CEP: 22290-240.

E-mail: ppbicalho@ufrj.br
\end{abstract}


of quantitative as a quantum forces and the notion of qualitative as differential between quanta of forces, in a real production.

Keywords: research methodology; method of cartography; quantitative, qualitative.

\section{1 - INTRODUÇão}

De acordo com uma classificação até certo ponto consagrada, as investigações qualitativas (quali) e quantitativas (quanti) são consideradas de natureza diferente (MINAYO; SANCHES, 1993), e, por isso se diz da possibilidade de integração entre um método e o outro, tendo em vista trazerem um olhar diferente sobre uma mesma realidade. A pesquisa quantitativa tende à verificação e mensuração de dados, assumindo, muitas vezes, uma realidade estatística devido ao uso de procedimentos controlados (MINAYO; SANCHES, 1993; SERAPIONI, 2000). Considera-se como ponto forte sua validade externa, já que os resultados são generalizáveis para grandes aglomerados de dados, que podem ser classificados e tornados inteligíveis por meio de variáveis. Já as pesquisas qualitativas focalizam as particularidades e especificidades dos grupos sociais estudados, de forma a entender os fenômenos a partir da perspectiva dos participantes, de conhecer de forma profunda suas vivências e as representações e interpretações que eles mesmos fazem dessas experiências (SERAPIONI, 2000; TURATO, 2005). Segundo Minayo e Sanches (1993) o material primordial da pesquisa qualitativa é a palavra, ou o material discursivo, capaz de revelar sistemas de valores, normas, símbolos, toda uma trama que aponta para as relações sociais. Reconhece ainda que entre as abordagens qualitativas as etnográficas privilegiam as etapas de observação participante e convivência no campo de pesquisa.

Entendemos que, sob essa classificação, a cartografia poderia se aproximar de algumas investigações qualitativas e se distanciar de outras. O distanciamento se coloca quando, nessas investigações qualitativas, privilegia-se o estudo dos fenômenos (valores, crenças, representações, opiniões, hábitos, atitudes) separados de sua dimensão processual de produção. A aproximação aconteceria na proporção do compartilhamento de preocupações e pressupostos implicados no processo da pesquisa, como, por exemplo: quando se busca "como o objeto de estudo acontece" (TURATO, 2005, p. 509); quando se trabalha com um nível de intensidade das relações sociais; quando se acompanha processos e se busca acessar a complexidade constitutiva de fenômenos específicos; e, ainda, quando a pesquisa se dedica ao estudo da configuração desses fenômenos ou processos, realizando, muitas vezes, uma imersão no campo de estudo, como se observa nas abordagens etnográficas (MINAYO; SANCHES, 1993). Etnografia e pesquisa cartográfica articulam-se no ethos relativo aos modos como seus pesquisadores se interessam e compõem com o campo de pesquisa, modo de convivência, de inclusão dos participantes, de relação com estes, de disponibilidade, configurando, portanto, uma atitude que se constrói no trabalho de campo (POZZANA; KASTRUP, 2009). Encontramos possibilidades de aliança e parceria em algumas das 
preocupações ético-políticas que movem esses processos de pesquisa, quando as investigações se fazem não apenas a partir de um vivido representacional; mas na articulação dos objetos de estudo a seu plano de produção.

Lembramos que a preocupação ética indica o exercício de uma atitude (FOUCAULT, 2006), de renovada atenção na direção de nosso pensamento e ações cotidianas, de questionamento em relação aos mundos e sujeitos que neles se atualizam. O compromisso nesse ponto é com a potência e efetuação da vida na abertura e diferenciação do ser. Desdobra-se a afirmação de uma política afirmadora da vida, que ativa a experiência de constituição de modos de existência singulares na aliança com o coletivo em nós. A inseparabilidade entre ética e política reposiciona as práticas de produção de conhecimento na direção crítico-criadora, abrindo condições transformadoras do que somos e fazemos.

Para a cartografia o método não se define por metas ${ }^{1}$ traçadas anteriormente, tampouco se delimita a partir desta ou daquela ferramenta de pesquisa, mas, sobretudo por um caminho e direção ético-política. Possibilita que no pesquisar os instrumentos sejam forjados, (re)situando-os sempre a partir do plano de relações que produz a pesquisa, não a partir de si mesmos. Desse modo, o que chamamos de "quali-quanti", na pesquisa cartográfica, "mais do que uma descrição formal dos métodos e técnicas a serem utilizados, indica as opções e a leitura operacional que o pesquisador fez do quadro teórico utilizado" (ARAGÃO; BARROS; OLIVEIRA, 2005, p. 20). Expressa também um jogo de forças constituinte do plano problemático da pesquisa.

Pensamos com Lourau e Lapassade (1975) que opor quantitativo a qualitativo, como dois métodos de pesquisa distintos, ainda que passíveis de integração, seria estabelecer os termos para um equívoco. Tal distinção diz respeito, efetivamente, à designação de:

[...] técnicas parciais, mais ou menos orientadas para o uso das matemáticas (ou, simplesmente, de dados estatísticos brutos) ou, então, para a utilização de variáveis não quantificadas (o que não significa que não possam ser quantificáveis) (LOURAU; LAPASSADE, 1975, p. 43).

A discussão do qualitativo e quantitativo torna-se interessante à pesquisa cartográfica, mas não se limita à classificação geral de instrumentos e estratégias, que definiriam um ou outro, ou à enumeração das vantagens e desvantagens também a estes relacionadas. A comparação entre os métodos, dentro dessa classificação, é muitas vezes focada na definição de qual deles seria mais ou menos científico ou qual método permitiria maior generalização, ou, ainda, quais instrumentos se prestariam para um ou outro método. Assim, uma parte significativa da literatura está preocupada apenas em focalizar a contraposição entre as duas abordagens. E, ainda, como se pode observar a partir da década de 1960, há estudos que se ocupam em mostrar o quanto eles podem ser complementares (SERAPIONI, 2000). 
Interessa-nos aqui propor uma discussão sobre quantitativo e qualitativo na ultrapassagem da perspectiva dicotômica "quali-quanti", tendo em vista o caráter incontornável assumido pela atenção ao plano de produção de subjetividade e objetividade, que os marca por sua provisoriedade e impermanência e os anima incessantemente. Entendemos, portanto, que uma problematização do quantitativo e do qualitativo pode nos auxiliar a ampliar nossos modos de fazer pesquisa.

Com isso, afirmamos que a pesquisa cartográfica, inclusive na montagem de seus instrumentos, possui o compromisso com o acesso à experiência, ${ }^{2}$ e não com a descrição, o mapeamento e a mensuração de um vivido separado de seu plano genealógico de produção. E, nessa direção, buscamos deslocar a discussão do qualitativo e do quantitativo para outras bases, que não são ancoradas na dicotomia quali-quanti e sim na articulação com o plano de inseparabilidade entre formas e forças, dando ênfase, sobretudo, ao aspecto quantitativo na relação com a pesquisa cartográfica.

Seguindo algumas linhas derivadas de outras pistas do método da cartografia, como invenção de dispositivos (KASTRUP; BENEVIDES DE BARROS, 2009), acesso à experiência (PASSOS; BENEVIDES DE BARROS, 2009a), ao coletivo de forças (ESCÓSSIA; TEDESCO, 2009), trabalhamos neste texto com essa diretriz: o quantitativo se refere ao próprio movimento de constituição do real. Em outras palavras, optamos por focar certos aspectos da relação "quantitativo e qualitativo" por dentro do próprio método da cartografia, considerando alguns pressupostos e movimentos que, momentaneamente, se apresentaram mais interessantes ao tratarmos a atividade de pesquisa do cartógrafo.

Sem ignorar o modo tradicional de classificação das pesquisas como quantitativas, formulamos uma discussão da noção desse quantitativo na relação com o plano das forças e o método da cartografia. Nessa direção, afirmamos aqui o quantitativo como quantum de força e o qualitativo como diferencial entre quanta de força (DELEUZE, 1976; NIETZSCHE, 1999; WHITEHEAD, 2006). Dizendo de outro modo, trata-se de distinguir sem separar o plano intensivo da experiência - o plano coletivo das forças (ESCÒSSIA; TEDESCO, 2009), plano movente da realidade, que se expressa por sua dimensão extensiva - e o plano das formas, plano de organização. Ressalta-se, desse modo, que a partir da pesquisa cartográfica o quantitativo e o qualitativo ganham sentido na articulação com a experiência, onde se dá a própria imbricação dos dois planos.

Considerar o quantitativo no âmbito da pesquisa cartográfica, para além de uma operação matemática abstrata (onde a processualidade da experiência resta separada e silenciada), desloca-nos para outra discussão. O quantitativo aponta para a inseparabilidade forma-força, extrapolando a dicotomia quali-quanti. $\mathrm{O}$ acompanhamento de processos e o acesso à experiência implica a invenção de mapas nos quais as relações entre quantidades de forças ganham contornos provisórios e se expressam em formas e sentidos. Ao afirmarmos a pesquisa cartográfica como acompanhamento de processos nos referimos necessariamente a processos que constituem planos de força, relação entre quantidades de força. 
Assim, como demonstrado no Gráfico a seguir, identificamos a cartografia com o traçado do plano intensivo das forças, na pesquisa que passa pelo acesso à experiência, independente se localizado na tradicional dimensão quali ou quanti.

\section{Gráfico 1}
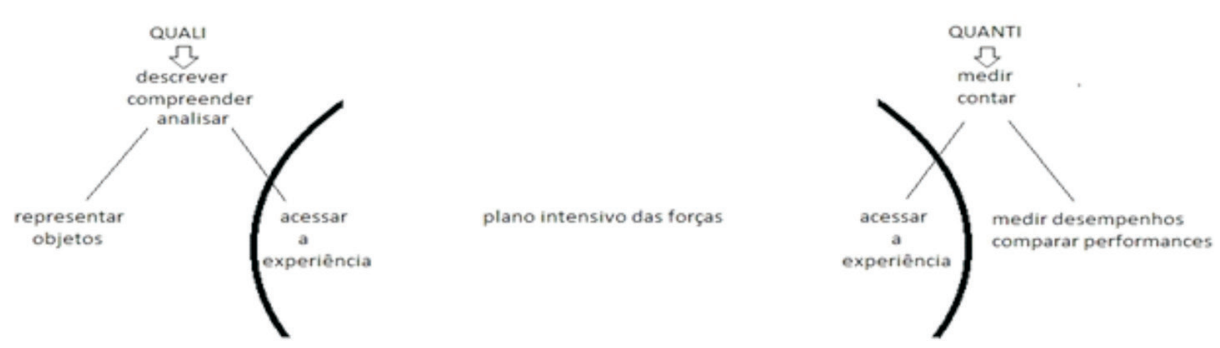

\section{2 - QUANDo o "QUANTI" É APARTADO DE SUA FORÇA}

Um debate extremamente importante, que tem nos ajudado a pensar as questões aqui apresentadas, diz respeito à problemática do uso dos testes psicológicos. A psiquiatra Hilda Morana (2003), em sua tese de doutorado defendida na Faculdade de Medicina da Universidade de São Paulo, traduziu e validou a "Escala Hare PCL-R - Psychopathy Checklist Revised" para seu uso no Brasil. Em 2005, a escala foi avaliada pelo Conselho Federal de Psicologia que, no mesmo ano, aprovou a sua utilização por meio da Comissão Consultiva que compõe o Sistema de Avaliação de Testes Psicológicos (SATEPSI).

O instrumento tem como propósito averiguar o grau de psicopatia presente na população carcerária por meio de uma entrevista semiestruturada "confiável e válida", segundo palavras do manual. Pontua o indivíduo ao longo de 20 itens eleitos para definir operacionalmente e assim reificar - tornar 'coisa a ser medida' - o conceito de psicopatia (dentre eles, "promiscuidade sexual" e "relacionamentos conjugais de curta duração") quantificando-os em uma escala de 3 pontos ( 0 , 1 ou 2) de acordo com o grau em que as respostas de um apenado se enquadram no conceito de psicopatia (inquirido por meio da entrevista). Importante apontar, desde já, o caráter processual do conceito reificado de psicopatia, bem como os itens utilizados, no teste, como critérios de avaliação de tal constructo. Direção oposta tomada pela escala que prioriza a análise da considerada estrutura da personalidade, sem considerar a conduta explícita (ou manifesta) do sujeito avaliado. Vale lembrar que, no Canadá, os sujeitos diagnosticados como psicopatas, a partir desse teste, são diretamente encaminhados à prisão perpétua, por serem considerados perigosos e irrecuperáveis.

O teste PCL-R tem sido apresentado como a solução para a prática do exame criminológico, e, assim, é afirmado como instrumento científico capaz de apontar futuras reincidências criminais e, desse modo, definir condições de regressão ou progressão da pena para indivíduos a partir de seu suposto grau de 
psicopatia. Yamada (2009) aponta que, apesar da pretensão de cientificidade e neutralidade, muitos profissionais atuantes no campo têm demonstrado que os instrumentos utilizados pela psicologia nos exames técnicos de criminosos revelam mais do que as chamadas características pessoais do examinando, como os estereótipos e preconceitos que circulam sobre a questão do crime e do criminoso. Além disso, repercutem em novas técnicas de controle da população, respaldando-se na sutileza do instrumental científico (RAUTER, 2003).

O PCL-R é apresentado como um instrumento sem história, sem atravessamentos sociais, políticos e econômicos, como uma máquina na qual somente é preciso inserir os dados e nela retirar os resultados necessários. Não importa como essa máquina funciona, como foi criada, tampouco a política de ciência em jogo e os mecanismos tecnológicos imbricados em seu funcionamento (YAMADA, 2009). Sua "validade" (e seu estatuto de fidedignidade) é atestada pelo cumprimento e pelo suposto rigor dos "métodos quantitativos" que se materializam pelas definições estatísticas de variância e desvio padrão. Assim, discussões epistemológicas ou ético-políticas são entendidas como "métodos qualitativos" que, por seu suposto "subjetivismo", não servem como argumentos para tornar recomendável um teste e, do mesmo modo, para afirmar sua não-recomendação. A discussão tradicional calcada na dicotomia quali e quanti acaba por inviabilizar uma discussão mais ampla nesse campo.

O que um teste, com uma pretensa verdade e neutralidade quantitativa, na medição do desempenho em relação à população carcerária termina por produzir? A discussão, quando restrita ao instrumento em si, encontra o risco de perder-se de seu campo de produção e produzir naturalizações. No caso em questão, a análise do PCL-R (e de outros testes psicológicos) se torna restrita aos chamados "métodos quantitativos" (tomados por instrumentos que operam por abstrações matemáticas), entendidos como descritores de "verdadeiros fatos científicos" que comprovam sua validade segundo "sérias e rígidas exigências científicas que atestam a sua confiabilidade" e os aprovados constructos psicométricos do teste. O que escapa aos critérios estatísticos é desconsiderado, por serem argumentos que serviriam "a outro tipo de método", o qualitativo, nesse caso. O resultado de um teste psicológico, contudo, efetivamente produz mundo, pois interfere na vida do avaliado: ao se conceder ou não a Carteira Nacional de Habilitação, o porte de armas ou a aprovação em um concurso público. Ou, ainda, ao se instituir um diagnóstico de hiperatividade e déficit de atenção ou de psicopatia.

A medida, em vez de representar um mundo verdadeiro, produz mundos. Logo, há uma dimensão quali nesse "território quanti", em todo o processo. Desse modo, não considerar as implicações ético-políticos e seus efeitos para a vida dos avaliandos, ao avaliar tal instrumento, parece-nos uma atitude questionável. Qual o sentido de se proceder uma avaliação somente por argumentos "quanti", dentro de uma classificação geral acerca do método? O que deixamos de fora? Neste exemplo, podemos inferir que a tradicional dicotomia quali-quanti produz efeitos políticos que devemos colocar em análise. 
Parece haver nessa dicotomia a suposição de um real verdadeiro que pode ser mensurado e uma transposição direta do concreto sensível para o ideal abstrato, como se a quantidade medida ou o ideal tomado como essência fosse de fato o concreto. As questões que nos interessam, de outro modo, interrogam os efeitos dessas práticas: como as "quantidades" de psicopatia acabarão por definir as relações com os presos? Quais condutas serão adotadas diante das "quantidades" constituintes desses corpos? Quais posturas e atitudes se atualizam diante daquilo que aparece como mensuração da própria existência nesses sujeitos? Que sujeitos e objetos se constituem nessa dinâmica conjugação de forças?

\section{3 - O Quantitativo e a Pesquisa Cartográfica}

Sujeitos e mundos são produtos “arbitrários", lembra Deleuze (1976), de arranjos de forças. Toda realidade é quantidade de força em relação de tensão umas com as outras. Todo objeto que elegemos é composto por uma multiplicidade de forças. Também para Nietzsche (1999) um objeto ou uma substância é uma ficção. São relações entre quantidades de forças - quantum. E por "força" entendemos ação, poder de transformação. Não a ação de um sujeito ou de uma matéria, mas a ação de uma força sobre a outra, que está no próprio processo de constituição do mundo.

Segundo Paschoal (1999, p. 52),

Um quantum não é algum tipo de matéria ou qualquer coisa que corresponda à ideia de "ser" (Daisen), mas algo que pode ser designado como "quantidades de ação", "proporções de querer", "força em ação". [...] um quantum designa ação, produção de efeito (wirkung), dinamicidade e relação (wirken) com outros quanta. Um quantum não remete a algo que permaneceria após a desagregação de uma unidade anteriormente dada e que juntamente com outros quanta, se reagregaria, formando novos corpos.

À quantidade, dizemos quantidade das forças. Não uma quantidade que funcione na lógica do número, divisível em partes menores. Mas, uma quantidade intensiva, que por isso melhor se define como quantum de força, "continuum de intensidades" (PASSOS; BENEVIDES DE BARROS, 2009b). A qualidade diz respeito ao diferencial entre as quantidades. Essa distinção entre o quantitativo e o qualitativo aponta para sua inseparabilidade, pois a toda diferença de quantidades corresponde uma qualidade. E desse modo que podemos, diante de formas constituídas, de sujeitos, objetos e saberes, perguntar: Como se produziu essa forma? Quais forças nela se movimentam? Qual a expressão desse arranjo de forças? As formas ou qualidades são expressão da luta entre as forças, de quanta de força, por isso são indissociáveis das quantidades. Nessa mesma direção, não há como acessar o plano das forças sem a avaliação das qualidades, das formas. E a avaliação diz respeito ao modo como a vida se expande ou se apequena. Não basta simplesmente afirmar ou negar outra noção de "quanti" ou "quali”, mas pensar estratégias de articulação dos efeitos da pesquisa com a própria vida. Interessa, 
nesse sentido, no caso de instrumentos como os testes, menos defini-los como "quanti" ou "quali", e mais, pensá-los como mobilização de quantidades de força, como efeitos que atualizam sujeitos e mundos. A crítica é a uma noção de quantidade como conceito abstrato que tende à anulação da diferença e a uma noção de qualidade que não seja expressão da relação entre as forças (DELEUZE, 1976).

O que nos interessa "é, do ponto de vista, da própria quantidade, a irredutibilidade da diferença de quantidade à igualdade" (DELEUZE, 1976, p. 36), a irredutibilidade das forças ao arranjo que faz surgir a forma. A qualidade é puro diferencial entre as forças. Medi-las é importante, mas não na direção de um sentido único para determinado fenômeno. Interessa que não se subsuma à forma, o coletivo de forças que nela é presente. Esse ponto é fundamental, pois quando utilizamos a abstração matemática em um uso puramente mecanicista, transformamos o que é da ordem da multiplicidade e da complexidade, em igualdade, e o que é da ordem da diferença, em semelhança. Em vez da tensão e provisoriedade que compõem o jogo do real, a unidade e a anulação das forças.

Isso conduz a um desdobramento da questão da medição, que aparece de forma diferente nos modos de abordar o "quanti" e "quali", que já enunciamos aqui. A medição no âmbito da dicotomia "quali-quanti" funciona como operação interpretativa da realidade. O qualitativo e o quantitativo serviriam para abordar facetas distintas da realidade (objetiva/subjetiva), como método definido a priori ou como instrumento para lidar com um real "quanti" ou "quali". Na dicotomia quali-quanti, trata-se de um trabalho limitado ao plano das formas já constituídas, que, separadas de seu plano genealógico, ilusoriamente, comparecem substancializadas, como coisas que se pode medir, esquadrinhar e identificar verdades. Sujeitos e objetos, nessa operação, são apartados da complexidade de sua história, que, ao contrário de uma placidez e imobilidade, indica, nos jogos de forças, enfrentamentos, rupturas, bloqueios e oportunidades.

Outro risco, nessa experiência de medição explicativa e redutora, é quando a pesquisa se propõe determinados problemas que, de saída, parecem conter pressupostos que buscam confirmação num real dado. Assim, espera-se que a pesquisa, sob a premissa de certo raciocínio, possa ser capaz de apontar o que deve ser realizado e a solução a ser "alcançada". Quando se busca, por exemplo, averiguar o grau de psicopatia nas populações carcerárias, há uma realidade recortada que é medida, como se a medição fosse o próprio real. A medição é tomada como aquilo que o preso é. Tal determinação traz consigo justificado um conjunto de práticas naturalizadas, além de expectativas de soluções quanto ao que fazer e como se relacionar com os presos - objetos da intervenção.

Afirma-se, aqui, a importância de uma atitude crítica, a ser também cultivada nos processos de pesquisa, que não se faz como prescrição vinda do alto ou como monopólio de alguns considerados mais "capacitados" que outros. Abordar a questão da quantidade é apontar para a dimensão de processualidade, provisoriedade que está na gênese das formas e que continua nelas presente. As formas objetivadas, sejam elas o cárcere, o prisioneiro, o teste ou a pesquisa, são efeitos de composições de forças. 
Apontamos essa atitude crítica, portanto, como outro modo de experiência de medição, que toca o "quanti" e "quali", na inseparabilidade entre forma e força. Faz-se, então, como criticismo de ação, como instrumento de luta, de resistência, de não querer mais as coisas como estão, como "desafio em relação ao que é" (FOUCAULT, 2010, p. 349), ao recorte do real e suas verdades pressupostas. Medir, nesse caso, é uma operação crítico avaliativa. É encontrar os pontos de fissuras e de quebra nas formas constituídas acessando um plano de quanta de forças em luta, imprevisível em seus efeitos (quali). É também intervir no presente dessas lutas.

Medir seria, então, pôr-se a caminho de um exercício de avaliação das forças em relação, em uma experiência que, como crítica, não se aproxima da ação judicativa. Medir, no sentido de avaliar, é afirmação de um processo de diferenciação que é a essência da força. A diferença de quantum é a própria essência da força. O instrumento PCL-R, por isso, menos que avaliar e exercitar a crítica, busca classificar uma realidade, a partir de um esquema descolado do concreto. $\mathrm{O}$ desafio da medição se faz a cada caso, avaliando concretamente, na composição das forças, sua qualidade respectiva e a nuance dessa qualidade, a diferença que o arranjo expressa (DELEUZE, 1976).

Essa experiência crítica não se faz ainda como monopólio ou privilégio de pesquisadores, ainda que os incluam, conclusões feitas por uns sobre a vida de outros, mas encontra sua efetivação no sujeito da ação, "da ação através da qual o real é transformado" (FOUCAULT, 2010, p. 349). A atitude crítica não se faz apenas por pesquisadores, mas é atitude a ser construída e efetivada por todos. É, por isso, um ethos que indica o caráter participativo na pesquisa e a geração coletiva dos problemas que, de fato, interessam e são interessantes a todos os que dela participam (DESPRET, 2011).

Por isso, podemos dizer que há sempre nas pesquisas, de modo geral, uma experiência de medição sendo atualizada, não sendo prerrogativa de uma pesquisa ou outra ou de instrumentos específicos para este fim, pois toda pesquisa, em seus procedimentos, produz determinados mundos e sujeitos. A pesquisa cartográfica, no entanto, compromete-se com a medição, na inseparabilidade forma-força, e no cultivo e exercício de uma atitude crítica.

\section{4 - UM EXERCÍCIO DE DEVOLVER O "QUANTITATIVO" AO QUANTUM DE FORÇAS}

O interesse pelo problema do quantitativo na pesquisa cartográfica remete ainda à importância da noção de dispositivo ${ }^{3}$ para esse método e das possibilidades de uso de instrumentos e procedimentos que daí advém. Um dispositivo, nas múltiplas linhas que o compõem, pode se prestar a usos diferenciados. Porém, um uso somente extensivista pode buscar no problema investigado unicamente o que se delineia como forma, como limite preciso, realizando uma medição de performance. Nesse uso, o extensivismo tenderia à qualidade, à forma, esvaziada de quantidades de força, de história; e as quantidades como independentes e equivalentes. 
A cartografia, de outro modo, afirma tanto o extensivismo quanto o intensivismo como duas políticas de narratividade inseparáveis, cada uma descrevendo certa "dimensão do objeto que se apresenta" - plano das formas, plano das forças (PASSOS; BENEVIDES DE BARROS, 2009b, p. 152). Ao considerar a dimensão extensiva do fenômeno investigado, como no caso que discutiremos na sequência, a pesquisa cartográfica tem como direção o acompanhamento de processos e o acesso ao plano das forças, ou seja, toma a extensão como efeito de um plano intensivo.

Recentemente (2010-2011), em pesquisa desenvolvida na rede municipal da Serra/ES pelo Programa de Formação e Investigação em Saúde do Trabalhador (PFIST)/UFES foi utilizado um questionário, ${ }^{4}$ que constitui um protocolo de procedimentos da OMS, para "mensurar" e diagnosticar transtornos mentais leves em educadores dessa rede. O instrumento bem validado nos dá como "resultado" a colocação de sujeitos-trabalhadores mais ou menos dentro de uma curva-normal; $20 \%$ dos professores apresentam o indicativo de transtorno mental leve, sendo que temos bem especificado o que compreende a categoria transtorno mental leve.

O instrumento utilizado parece de saída já apontar seu resultado, pois já se sabe que o que busca é o diagnóstico de transtorno mental e, obviamente, poderia ser também o que, unicamente nos daria a ver, não fosse a problematização realizada dentro deste Programa quanto ao instrumento e quanto ao processo de produção dos seus resultados. Entendemos que há, prioritariamente, na construção desse instrumento, uma direção de uso extensivista, assim como no PCL-R, no qual a busca inicial é pela redundância, pela semelhança e pela possibilidade de realização de análises estruturais e generalizadas seja sobre a população carcerária ou sobre os trabalhadores da educação de um determinado município. Opera, portanto, a partir de um quantitativo substancializado, que termina por igualar e uniformizar todo um campo de forças.

Entretanto, o que interessava na pesquisa realizada não era apenas a produção de um dado, ou o instrumento e sua capacidade de gerar equivalências infinitamente, mas, a potência desse material, no sentido de favorecer um ponto de articulação com os trabalhadores, um objeto comum que fosse passagem para inflexões no desenrolar dos processos de trabalho na educação. Foram utilizados gráficos e estatísticas para fomentar análises coletivas dos processos de trabalho.

Portanto, para o diálogo com os trabalhadores parecia importante construir condições de visibilidade à luta de forças que atravessa e compõe o campo problemático, inclusive em seus efeitos de sofrimento, nos processos reativos que produzem despontencialização (o apartamento da força daquilo que ela pode, de seu poder de agir). Os gráficos tornaram-se um importante ponto de partida para compor um processo de análise coletiva da atividade do professor, sendo que, naquele momento, ajudou a compor um objeto comum, uma narratividade que tivesse sentido para os trabalhadores e para a própria Secretaria de Educação do município. De outro modo, poder-se-ia não conseguir avançar com a pesquisa e seus objetivos de fomentar espaços de análise coletiva dos processos de trabalho, buscando, nessa direção, construir junto aos trabalhadores outras estratégias. Com isso, ressaltamos apenas que o uso da matemática pode se dar bem se arti- 
culado com o plano problemático. Não se trata de negar ou abolir este ou aquele instrumento. Trata-se de articulá-los sempre no plano mais amplo dos problemas que envolvem e produzem a pesquisa, atento ao modo como deles se faz uso, de forma a retirá-los sempre de uma perspectiva per si, prêt-à-porter, como se já viessem prontos para uso, operando-os, assim, como dispositivo mais amplo, muitas vezes incluído ou incluindo outros dispositivos.

$\mathrm{O}$ esforço maior na pesquisa com educadores foi o de problematizar inicialmente, na equipe de pesquisa, os sentidos do questionário e sua articulação com os outros processos em andamento, quais pesquisadores estariam envolvidos, quais escolas participariam, como envolver a Secretaria de educação neste processo. Enfim, todo um trabalho de retirada do instrumento de um lugar já dado, fazendo-se como dispositivo mais amplo.

Porém, foi preciso um cuidado: os dados poderiam funcionar como denúncia e como representação dos comportamentos e sentimentos, sob o risco de a relação entre os gráficos, com números alarmantes, e a experiência de sofrimento se reduzir a uma análise individualizada, limitada ao plano das formas. A abordagem cartográfica impunha um exercício contínuo de articular, conforme direção apontada neste texto no Gráfico 1, dimensão intensiva e extensiva, força e forma - retomar assim na pesquisa a relação da abstração dos números com o plano coletivo das forças. Os gráficos e os números foram incluídos na pesquisa como índice intensivo desse plano mais ampliado: estratégias de avaliação dos efeitos da pesquisa e criação de dispositivos.

Limitar a análise ao corte pressuposto no instrumento (dado como representação do mundo) torna o pesquisador ignorante de outros pontos importantes, como as invenções de estratégias, as redes solidárias e cooperativas e processos de produção de saúde. Buscava-se o plano das forças, as microlutas, que expressam o quantum de forças, o continuum de intensidades. Cabia, portanto, uma análise mais ampliada a fim de avaliar o dispositivo criado. Assim, os possíveis "resultados", conjugados à expressividade estatística, articulavam-se a outras questões que continuavam por ampliar a discussão em vez de se fechar em um diagnóstico.

Se havia, por exemplo, um gráfico em que $75,4 \%$ dos educadores respondiam afirmativamente ao fato de dependerem de outras pessoas para realizar adequadamente seu trabalho, havia outro ainda que mostrava que apenas $26 \%$ consideravam satisfatórias tais relações. No caso dos dois gráficos mencionados, havia uma abertura para que pudéssemos pensar que há um plano de interdependência e inseparabilidade que sustenta os processos de trabalho, perceptível à maior parte dos trabalhadores, mas, nem por isso, vivível e praticável. O que se considera insatisfatório nas relações? Quais as expectativas de uns sobre os outros e ainda sobre a atividade de trabalho? Outras estratégias a serem inventadas mostravam-se necessárias para o tratamento de tais questões.

Nessa pesquisa, a extensividade só fez sentido quando aliançada a uma política intensivista, assim como não interessava privilegiar apenas um instrumento em detrimento de outros. Sem cair em um extremo ou outro, o caminho do entre 
nos permite pensar a importância das diferentes estratégias, desde que situadas em um dispositivo mais amplo, capaz de analisar a composição das linhas e das forças diferentes que atravessam e compõem a pesquisa.

\section{5 - CONSIDERAÇÕES FINAIS}

A ampliação desse debate parece-nos cada vez mais importante no que toca às políticas de produção de pesquisa na atualidade. Recolocar a discussão sob outras bases, que não a partir dos instrumentos per si ou de uma suposta dicotomia "quali-quanti", mas a partir de uma direção ético-política. Por isso, na pesquisa cartográfica, do mesmo modo como se afirma o método em sua dimensão processual ou a construção de objetos que surgem agenciados aos modos como se pesquisa, também as dimensões quantitativa e qualitativa fazem sentido em sua inseparabilidade constituinte, operando ainda um plano de invenção de estratégias que permitam acesso à multiplicidade da experiência.

Esse é o desafio: sair da dicotomia, sem abandonar a dualidade "quali-quanti" como dimensões constitutivas do real, como jogos de forças e a expressão desses. Esse modo de colocar a questão traz à cena um fazer situado, de modo que as expressões dos jogos de força não são a última palavra sobre o real, são sempre passagens e conjunções. As qualidades, no plano das formas, não são representações de um real dado e acabado, ou a correspondência do mundo à expectativa do pesquisador. A direção ética reside nessa possibilidade de avaliar os efeitos do próprio pesquisar em articulação com o modo como se pesquisa, como surgem sujeitos e objetos nessa experiência. O político na dimensão ética nos convida a observarmos nossas práticas e ainda a correlação de forças que permite um dispositivo funcionar. É a este movimento, o das práticas, que é necessário pensar e intervir.

É articulando a pesquisa com um fazer-situado que o quantitativo e o qualitativo podem não equivaler a instrumentos e ferramentas utilizados. $\mathrm{O}$ acompanhamento e acesso ao "quali" e ao "quanti", como dimensões imbricadas, possibilitam a invenção de estratégias, onde importa a avaliação de seus efeitos. Como os dispositivos montados articulam-se aos problemas que fazem a pesquisa, o que produzem?

Chama a atenção nas discussões mais atuais, que ainda que quantitativo e qualitativo se apresentem em uma perspectiva de complementaridade e integração, resguarda-se uma separação muito clara em relação aos procedimentos. Afirma-se uma integração, mas os instrumentos e técnicas e o próprio método continuam operando uma divisão. Quando a questão do "quali-quanti” é deslocada para além da dicotomia ou da integração, como planos de inseparabilidade de produção do real, desdobra-se também a possibilidade de retirada dos dispositivos de pesquisa de uma classificação apriorística, quantitativos ou qualitativos, ou das funções de medir, contar e/ou descrever, compreender, analisar. Ao contrário, os dispositivos, em vez de distribuídos em um ou outro método ou função, puramente uma coisa ou outra, portariam as duas dimensões, tanto uma face intensiva quanto extensiva, e isso não dividiria o dispositivo, ao contrário, 
abriria possibilidades de múltiplos usos, afirmando seu caráter de hibridismo. No dispositivo, portanto, intensivo-extensivo, força-forma, quanti-quali, comparecem como afirmação do caráter híbrido de constituição do real.

Os dois casos trabalhados neste texto apontam para os efeitos de se considerar a dicotomia "quali-quanti" ou a dualidade forma-força. Quando há a manipulação do instrumento per si ou a tentativa de fazer caber a pesquisa em uma classificação geral, parece haver já de início um mundo pronto a ser investigado, que se supõe substancializado e idealmente isolado. A atividade de pesquisar torna-se a medição (interpretação) da correspondência e fidedignidade dos produtos da pesquisa à expectativa do pesquisador. Os objetos e sujeitos são arrancados de sua processualidade.

Tradicionalmente, os parâmetros psicométricos, que conferem o atual status de "teste recomendável", como o PCL-R, pelo Conselho Consultivo do Sistema de Avaliação de Testes Psicológicos estão embasados unicamente em critérios estatísticos, tornando o teste uma forma vazia de força. Embora, em última instância, esteja claramente compondo a produção de "mundos verdadeiros". Portanto, a utilização, na pesquisa cartográfica, de ferramentas tradicionalmente consideradas como quantitativas, podem ou não abrir o trabalho de formulação e ampliação dos problemas em questão. Disso dependerá o uso desses dispositivos, no compromisso ético-político de experimentação em seu caráter híbrido, buscando para além de determinações causais e exatas, proximidades e velocidades relativas aos arranjos de quantidades de força sempre provisórias. No caso da pesquisa com os docentes, a dimensão extensiva do dispositivo montado, na utilização da estatística, permitiu visibilizar questões importantes. Possibilitou pensar o "número" como quantitativo, no sentido de quantum. O número é uma abstração (WHITEHEAD, 1969, 2006), mas possível de articulação com o quantitativo das forças que também o produzem, sua dimensão intensiva.

Há de se acrescentar ainda uma indicação: optar pelo trabalho com a política extensivista, ou ainda com instrumentos que visam extrair, medir, contar e, ainda, possibilitam uma ampla generalização de resultados, exige um redobrado cuidado. A pesquisa em educação o solicitou, pois a abstração dos números e o recorte possibilitado criava a ilusão de se saber "verdadeiramente" sobre algo, entender "melhor" uma realidade. O cuidado é este de buscar os limiares, a luta de forças, que não se presta à medição interpretativa e representacional. Tratava-se, então, de exercitar e sustentar uma atitude-crítica, como experiência de medição, acercar-se do ethos que produz a pesquisa a fim de dissolver a presunção positivista, para afirmar o quantum de forças, a multiplicidade do real.

Desse modo, o real em sua produção é marcado por uma batalha que mora na gênese dos acontecimentos, um combate "contra tudo aquilo que ele teria podido ser, mas não é" (ROQUE, 2008, p. 107). Interessa na análise da relação entre quantidades de força que produzem os acontecimentos, menos o "por quê?" e mais o "como". Esta parece ser uma pista para o exercício da avaliação, do diferencial entre as forças (da qualidade). Não se trata de medir para entender, explicar ou reconhecer um mundo dado. Trata-se de acessar o plano das forças 
para avaliar os efeitos das relações, e como fazem vibrar um mundo. Uma boa pista, portanto, para a prática da cartografia não seria a dicotomia "quali-quanti", mas a inseparabilidade forma-força.

\section{Notas}

${ }^{1}$ Embora o pesquisar não parta do ponto zero, mas se constrói a partir de um patrimônio, de uma história, de outras experimentações. Quando dizemos que as metas não se encontram prontas é que as direções da pesquisa são inseparáveis de como o campo se constitui, dos problemas que emergem. ${ }^{2}$ Lembramos que o plano da experiência, de produção ou coemergência, é dimensão processual cujo primado é o das relações, agenciando sujeitos e objetos, teoria e prática, e como veremos, quantitativo e qualitativo. Ver mais em Passos e Benevides de Barros (2009a).

${ }^{3}$ Sobre a importância do dispositivo na pesquisa cartográfica ver Kastrup e Benevides de Barros (2009). ${ }^{4} \mathrm{O}$ Questionário utilizado corresponde a um inquérito epidemiológico com levantamento de dados relacionados às seguintes variáveis: aspectos sociodemográficos, percepção sobre saúde e trabalho, situações relacionadas à saúde mental baseado no Self Report Questionnaire (SRQ 20).

\section{REFERÊNCIAS}

ARAGÃO, E. M.; BARROS, M. E. B.; OLIVEIRA, S. P. Falando de metodologia de pesquisa. Estudos e pesquisas em psicologia, Rio de Janeiro: ano 5, n. 2, p. 18-28, 2005.

POZZANA, L.; KASTRUP, V. Cartografar é acompanhar processos. In: PASSOS, E.; KASTRUP, V.; ESCÓSSIA, L. da. (Org.). Pistas do método da cartografia: pesquisa-intervenção e produção de subjetividade. Porto Alegre: Sulina, 2009. p. $52-75$.

DELEUZE, G. Nietzsche e a filosofia. Rio de Janeiro: Rio/SEMEION, 1976.

DESPRET, V. Leitura etnopsicológica do segredo. Fractal: Revista de Psicologia, Niterói, v. 23, n. 1, p. 5-28, jan./abr. 2011.

ESCÓSSIA, L. da; TEDESCO, S. O coletivo de forças como plano de experiência cartográfica. In: PASSOS, E.; KASTRUP, V.; ESCÓSSIA, L. da. (Org.). Pistas do método da cartografia: pesquisa-intervenção e produção de subjetividade. Porto Alegre: Sulina, 2009. p. 92-108.

FOUCAULT, M. A hermenêutica do sujeito. São Paulo: Martins Fontes, 2006.

FOUCAULT, M. Mesa redonda em 20 de Maio de 1978. In: MOTTA, M. B. da (Org.). Estratégia, poder-saber. Rio de Janeiro: Forense Universitária, 2010. Coleção Ditos \& Escritos, v. 4, p. 335-351.

KASTRUP, V.; BEVEVIDES DE BARROS, R. Movimentos-funções do dispositivo na prática da cartografia. In: PASSOS, E.; KASTRUP, V.; ESCÓSSIA, L. da (Org.). Pistas do método da cartografia: pesquisa-intervenção e produção de subjetividade. Porto Alegre: Sulina, 2009. p. 76-91. 
LOURAU, R.; LAPASSADE, G. Para um conhecimento da sociologia. Lisboa: Assírio \& Alvim, 1975.

MINAYO, M. C. S; SANCHES, O. Quantitativo-qualitativo: oposição ou complementariedade? Cad. Saúde Pública, Rio de Janeiro, v. 9, n. 3, p. 239-262, jul./set., 1993.

MORANA, H. C. P. Identificação do ponto de corte para a escala PCL-R (Psychopathy Checklist Revised) em população forense brasileira: caracterização de dois subtipos de personalidade; transtorno global e parcial. 2003. 178f. Tese (Doutorado) - Faculdade de Medicina, Universidade de São Paulo. São Paulo, 2003.

NIETZSCHE, F. W. Genealogia da moral: uma polêmica. São Paulo: Companhia das Letras, 1999.

PASCHOAL, A. E. A dinâmica da vontade de poder como proposição moral nos escritos de Nietzsche. 1999. 272 f. Tese (Doutorado)-Departamento de Filosofia do Instituto de Filosofia e Ciências Humanas da Universidade Estadual de Campinas, Campinas (SP), 1999.

PASSOS, E; BENEVIDES DE BARROS, R. A cartografia como método de pesquisa-intervenção. In: PASSOS, E.; KASTRUP, V.; ESCÓSSIA, L. da (Org.). Pistas do método da cartografia: pesquisa-intervenção e produção de subjetividade. Porto Alegre: Sulina, 2009a. p. 17-31.

PASSOS, E.; BENEVIDES DE BARROS, R. Por uma política da narratividade. In: PASSOS, E.; KASTRUP, V.; ESCÓSSIA, L. da (Org.). Pistas do método da cartografia: pesquisa-intervenção e produção de subjetividade. Porto Alegre: Sulina, 2009b. p. 150-171.

RAUTER, C. M. B. Criminologia e Subjetividade no Brasil. Rio de Janeiro: Revan, 2003.

ROQUE, T. Isabelle Stengers. Penser avec Whitehead: une libre et sauvage creation de concepts (resenha). Revista Brasileira de História da Ciência, Rio de Janeiro, v. 1, n. 1, p. 106-111, jan.-jun. 2008.

SERAPIONI, M. Métodos qualitativos e quantitativos na pesquisa social em saúde: algumas estratégias para a integração. Ciência \& Saúde Coletiva, [S.1.], v. 5, n. 1, p.187-192, 2000.

TURATO, E. R. Métodos qualitativos e quantitativos na área da saúde: definições, diferenças e seus objetos de pesquisa. Rev. Saúde Pública. São Paulo, v. 39, n. 3, p. 507-514, 2005. 
WHITEHEAD, A. N. Os fins da educação e outros ensaios. São Paulo: Nacional / USP, 1969.

WHITEHEAD, A. N. A ciência e o mundo moderno. São Paulo: Paulus, 2006.

YAMADA, L. T. O horror e o grotesco na psicologia: avaliação de psicopatia através da Escala Hare - PCLR. 2009. Dissertação (Mestrado em Psicologia)Programa de Pós-Graduação em Psicologia, Universidade Federal Fluminense, Niterói, 2009.

Recebido em: 05 de maio de 2013 Aceito em: 10 de julho de 2013 